\title{
Angiotensin II Binding Sites in Individual Segments of the Rat Nephron
}

\author{
Salim K. Mujais, Susan Kauffman, and Adrian I. Katz \\ Department of Medicine, University of Illinois at Chicago, Chicago, Illinois 60612; and Department of Medicine, The University of \\ Chicago Pritzker School of Medicine, Chicago, Illinois 60637
}

\begin{abstract}
The sites of action of angiotensin II along the nephron are not well defined and both proximal and distal effects are suggested. Using a microassay that permits measurement of hormone binding in discrete tubule segments, we determined the binding sites of ${ }^{125} \mathrm{I}$-angiotensin II along the nephron of Sprague-Dawley rats. Specific binding in proximal convoluted tubule (PCT) (at $25^{\circ} \mathrm{C}$, pH 7.4) was linearly related to tubule length and saturable, with an apparent maximal binding capacity of $\sim 300 \mathrm{amol} \cdot \mathrm{cm}^{-1}$. Binding specificity was verified in competition experiments that revealed significant $(P<0.001)$ and comparable competition for radioligand binding by angiotensin II and angiotensin precursor, metabolite, and analogues, whereas unrelated peptides of similar size (bradykinin, ACTH [1-10]) were without effect. The profile of specific angiotensin II binding along the nephron was: PCT, 216 \pm 13 ; pars recta, 86 \pm 14 ; medullary thick ascending limb of Henle's loop, 46 \pm 8 ; cortical thick ascending limb of Henle's loop, $77 \pm 8$; distal convoluted tubule, $49 \pm 10$; cortical collecting tubule, 15 \pm ; medullary collecting tubule, $32 \pm 7 \mathrm{amol} \cdot \mathrm{cm}^{-1}$. These results indicate the presence of specific angiotensin II binding sites in all tubule segments studied, but binding capacity was highest in the proximal convoluted tubule, in agreement with transport studies that localize the effects of the hormone in this segment.
\end{abstract}

\section{Introduction}

Angiotensin II (AII) ${ }^{1}$ influences both renal hemodynamics (1) and tubular transport processes (2), but its effects on the latter are incompletely defined. Although clearance studies provided circumstantial evidence for a tubular effect of AII at both proximal and distal nephron sites, the nature of this interaction remains controversial. In micropuncture studies in the rat $(3,4)$ the findings were again variable, ranging from inhibition (3) to stimulation of transport (4), and including a dose-dependent bimodal effect (5) that probably explains the divergent findings. The early negative findings in isolated perfused rabbit proximal

Address reprint requests to Dr. Mujais, Section of Nephrology, Department of Medicine, Northwestern University Medical School, 303 East Chicago Ave., Chicago, IL 60611.

Received for publication 13 August 1985.

1. Abbreviations used in this paper: $\mathrm{AII}$, angiotensin II; PCT, proximal convoluted tubule(s); PR, pars recta.

J. Clin. Invest.

(c) The American Society for Clinical Investigation, Inc.

$0021-9738 / 86 / 01 / 0315 / 04 \$ 1.00$

Volume 77, January 1986, 315-318 tubules (6) have been ascribed to degradation of AII by serum angiotensinases present in the bathing medium, since recent studies utilizing artificial bath solutions described an electroneutral stimulation of fluid transport (7).

Although these reports suggest a dose-dependent bimodal effect of angiotensin II at multiple sites along the nephron, they do not define the exact tubular sites of action of the hormone. Binding sites for AII have been identified in the glomerular tuft (8), renomedullary interstitial cells in tissue culture (9), renal tubular cell fragments (10-13), and bovine kidney proximal tubule cell culture (14). However, these studies were performed utilizing heterogenous preparations and thus do not identify the target nephron segment(s) affected by the hormone. The present study was undertaken to determine the binding sites of AII along the rat nephron using a microassay that permits measurement of hormone binding in discrete nephron segments.

\section{Methods}

Tubule microdissection. Kidneys were obtained from 68 Sprague-Dawley rats weighing $180-200 \mathrm{~g}$ and fed regular laboratory chow ad lib. until study. Procedures for tissue preparation and tubule microdissection have been previously described (15) and will be presented briefly. Under pentobarbital anesthesia the left kidney was perfused with a cold collagenasecontaining solution $\left(\mathrm{NaCl}, 137 \mathrm{mM} ; \mathrm{KCl}, 5 \mathrm{mM} ; \mathrm{MgSO}_{4}, 0.8 \mathrm{mM}\right.$; $\mathrm{Na}_{2} \mathrm{HPO}_{4}, 0.33 \mathrm{mM} ; \mathrm{KH}_{2} \mathrm{PO}_{4}, 0.44 \mathrm{mM} ; \mathrm{MgCl}_{2}, 1 \mathrm{mM} ; \mathrm{CaCl}_{2}, 1 \mathrm{mM}$; Tris-HCl, $10 \mathrm{mM}$; collagenase, type I (Sigma Chemical Co., St. Louis, MO), $400 \mathrm{U} / \mathrm{ml}$; and bovine serum albumin, $0.05 \%$; $\mathrm{pH}$ 7.4). Thin pyramids were cut along the corticopapillary axis and incubated for 7 min in the same medium at $35^{\circ} \mathrm{C}$, after which they were rinsed with cold microdissection solution $\left(\mathrm{NaCl}, 100 \mathrm{mM} ; \mathrm{MgCl}_{2}, 4 \mathrm{mM}\right.$; Tris- $\mathrm{HCl}$, $50 \mathrm{mM}$; dithiothreitol, $2 \mathrm{mM}$; bovine serum albumin, $0.5 \%$; $\mathrm{pH} \mathrm{7.4).}$ Segments from different parts of the nephron were dissected freehand under stereomicroscopic observation, transferred to a sunken bacteriologic slide, and photographed to determine their length.

${ }^{125}$ I-Angiotensin II binding assay. Experiments were done using proximal convoluted tubules to determine optimal temperature, hormone concentration, and incubation time for the binding assay. The composition of the incubation solution used was identical to that used in microdissection above, except for the addition of radioligand and unlabeled hormone. The angiotensinase inhibitor dithiothreitol was added to both the microdissection and the incubation solutions to minimize AII degradation.

Several tubules from the same nephron segment (average total length, 3-5 $\mathrm{mm}$ ) were pooled in each sample and placed on small pieces of aluminum foil in wells of an aluminum plaque. The microdissection solution was then aspirated and replaced by $2 \mu \mathrm{l}$ of cold incubation medium using an automatic Hamilton dispenser. Incubation was started by immersing the plaques in a water bath at $25^{\circ} \mathrm{C}$, and was carried out for $30 \mathrm{~min}$ without agitation. Incubation was stopped by cooling on ice. The incubation medium was aspirated and the tubules were washed four times with $2 \mu \mathrm{l}$ of a cold stop solution containing $50 \mathrm{mM} \mathrm{MgCl}, 300$ $\mathrm{mM} \mathrm{NaCl}$, and $50 \mathrm{mM}$ Tris, $\mathrm{pH}$ 7.4. After the final rinsing, the solution 
was completely removed, the pieces of aluminum foil containing ths tubules were transferred to counting vials, and the radioactivity was counted in a gamma counter (Beckman Biogamma, Bria, CA).

To allow assessment of the binding of AII to other cell components including luminal membranes, osmotic shock was performed in separate experiments before the binding assay as follows: After transfer of the tubules to the aluminum wells, the microdissection solution was aspirated and replaced with $2 \mu \mathrm{l}$ of distilled water. At the end of $5 \mathrm{~min}$ the hypotonic solution was removed, the incubation solution was added, and experiments were carried out as described above.

To determine the specificity of AII binding, PCT were incubated in the presence of 1,000-fold excess unlabeled AII, AII analogues (Sar'$\mathrm{Ala}^{8}$-angiotensin II, $\mathrm{Sar}^{1}$ - $\mathrm{Thr}^{8}$-angiotensin II), angiotensin I, angiotensin III, and unrelated peptide hormones of similar molecular weight (bradykinin, ACTH [1-10] fragment). Angiotensin converting enzyme inhibitor was added to the incubation medium (final concentration, $1 \mathrm{mM}$ ) when displacement by angiotensin I was performed.

Calculations. ${ }^{125}$ I-angiotensin II binding was determined in each animal in quadruplicate, each sample consisting of 3-5 $\mathrm{mm}$ of tubule, and all tubules of a particular segment from a single animal represent a single data point in the figures. In addition, blanks (incubated without tubules) were used for each assay condition. Adherence of the labeled hormone to aluminum foil was negligible. Binding is expressed as attomoles ${ }^{125} \mathrm{I}$ angiotensin II bound per centimeter of tubule using the following formula: bound ${ }^{125} \mathrm{I}$-angiotensin II $=\left(\mathrm{X}-\mathrm{X}_{0}\right) \cdot(\mathrm{L} \cdot \mathrm{SRA})^{-1}$, where $\mathrm{X}$ is the measured radioactivity (counts $/ 20 \mathrm{~min}$ ) of the sample; $X_{0}$ is the mean counts of the blanks; $L$ is the length of the tubule in $\mathrm{cm}$; and SRA is the specific radioactivity of ${ }^{125} \mathrm{I}$-angiotensin II in counts per $20 \mathrm{~min}$ per attomole. Specific binding was calculated from the difference between the total binding (measured in the presence of ${ }^{125} \mathrm{I}-\mathrm{AII}$ alone) and the nonspecific binding (measured in the presence of 1,000-fold excess unlabeled AII). Counts per minute of total binding ranged between seven times the background counts in proximal convoluted tubules (PCT) and two to three times the background counts in cortical collecting tubules (CCT). Examples of actual counts per $20 \mathrm{~min}$ for total and nonspecific binding, respectively, were 5,900 and 3,100 in PCT, and 2,050 and 1,600 in CCT; background counts averaged $820 / 20 \mathrm{~min}$.

To verify the appropriateness of normalizing binding per unit length of tubule, we examined in preliminary experiments the relationship between the two variables. PCT segments of variable total length (2.2-11.0 $\mathrm{mm}$ ) were used. Binding was found to be highly correlated with tubule length $(r=0.93, P<0.001)$, and therefore was expressed in all subsequent experiments in $\mathrm{amol} \cdot \mathrm{cm}^{-1}$.

Materials. (Tyrosyl- ${ }^{125}$ I)-(5-L-isoleucine)-AII (specific activity, 1,880 $\mu \mathrm{Ci} / \mu \mathrm{g}$ ) was purchased from New England Nuclear, Boston, MA. AII, Des-Asp ${ }^{-1}$-angiotensin I, $\mathrm{Val}^{4}$-angiotensin III, $\mathrm{Sar}^{1}$-Ala ${ }^{8}$-angiotensin II, $\mathrm{Sar}^{1}$-Thr ${ }^{8}$-angiotensin II, angiotensin converting enzyme inhibitor (GluTrp-Pro-Arg-Pro-Gln-Ile-Pro-Pro), bradykinin, and ACTH [1-10] fragment were purchased from Sigma Chemical Company.

Statistical methods. Statistical analysis was done using the paired Student's $t$ test. Values are expressed as mean \pm SEM.

\section{Results}

The temporal profile of binding in PCT at different temperatures is depicted in Fig. 1. At $4^{\circ} \mathrm{C}$ binding was minimal throughout the period of observation. This finding allowed us to consider that rapid cooling of the tubules on ice can be equated with termination of the incubation period. At $25^{\circ} \mathrm{C}$, total and specific binding increased rapidly, reached a peak at $30 \mathrm{~min}$, and showed a slow decline thereafter. At $37^{\circ} \mathrm{C}$, total binding also peaked at $30 \mathrm{~min}$. In contrast to the findings at $25^{\circ} \mathrm{C}$, however, nonspecific binding continued to increase with time. Specific binding decreased significantly after $15 \mathrm{~min}$, a finding consistent with a limited stability of the angiotensin receptor or of the receptorligand complex at this temperature.
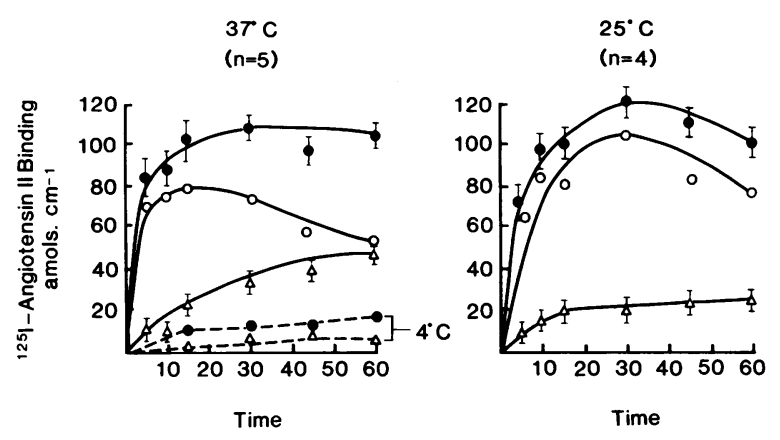

Figure 1. Time course of ${ }^{125} \mathrm{I}$-angiotensin II binding in PCT at different temperatures. Specific binding was highest at $25^{\circ} \mathrm{C}$. $\bullet$, total; $\Delta$, nonspecific; $\bigcirc$, specific.

The effects of increasing concentrations of labeled AII on binding in PCT are shown in Fig. 2. A progressive increment in total, specific, and nonspecific binding was observed with increases in free ligand until a concentration of $8-9 \mathrm{nM}$ was reached. Beyond this level, no further increase in specific binding was observed, while total and nonspecific binding increased more slowly and in tandem. The apparent maximal binding capacity of the PCT estimated from this plot was $\sim 300 \mathrm{amol} \cdot \mathrm{cm}^{-1}$.

The profile of specific ${ }^{125} \mathrm{I}$-angiotensin II binding along the rat nephron is shown in Fig. 3. For these studies, a radioligand concentration of 5-6 $\mathrm{nM}$ was chosen because it was sufficient to allow reproducible measurements in all nephron segments. Specific binding was highest in the PCT, followed by the pars recta $(P R)$ and the cortical and medullary portions of the thick ascending limb of Henle's loop. Very high specific binding was also identified in dissected glomeruli (302 \pm 13 amolglomerulus $\left.^{-1}\right)$. Nonspecific binding was also highest in the PCT $\left(69 \mathrm{amol} \cdot \mathrm{cm}^{-1}\right)$ followed by PR $\left(30 \mathrm{amol} \cdot \mathrm{cm}^{-1}\right)$, and it ranged between 6 and $19 \mathrm{amol} \cdot \mathrm{cm}^{-1}$ in the more distal segments of the nephron. Disruption of proximal tubule cell integrity by short exposure to a hypotonic medium significantly increased total binding (radioligand concentration, $3.5 \mathrm{nM}$ ) from $90 \pm 10$

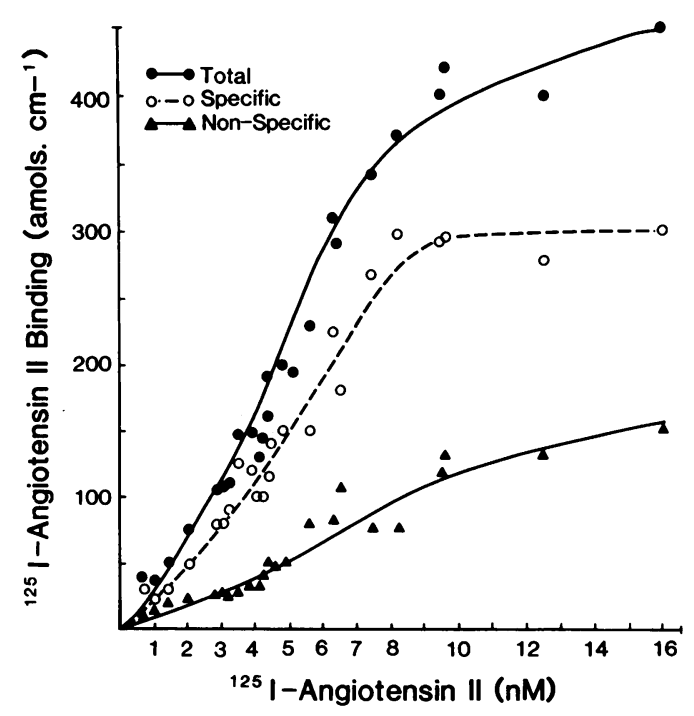

Figure 2. Binding of ${ }^{125} \mathrm{I}$-angiotensin II in PCT at varying ligand concentrations determined in 10 animals. The apparent maximal binding capacity is $\sim 300 \mathrm{amol} \cdot \mathrm{cm}^{-1}$. $\bullet$, total; $\circ$, specific; $\triangle$, nonspecific. 


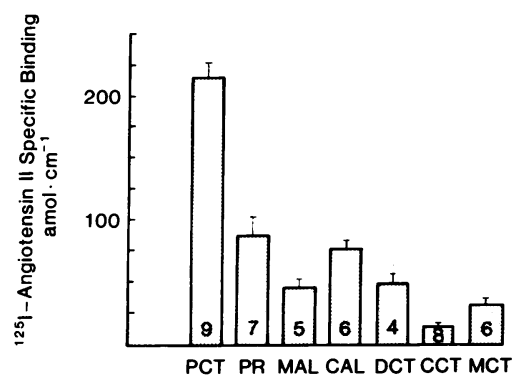

Figure 3. Profile of ${ }^{125} \mathrm{I}$-angiotensin II binding in seven nephron segments. Significant specific binding $(P<0.001$ vs. zero) was identified in all nephron segments studied. Number of animals is given in bars.

to $301 \pm 32 \mathrm{amol} \cdot \mathrm{cm}^{-1}(P<0.001)$, specific binding from $74 \pm 9$ to $278 \pm 25 \mathrm{amol} \cdot \mathrm{cm}^{-1}(P<0.001)$, with a more modest inc rement in nonspecific binding from $24 \pm 1$ to $47 \pm 3 \mathrm{amol} \cdot \mathrm{cm}^{-1}(P$ $<0.001$ ).

Competition experiments were done to determine the specificity of the AII binding measured in PCT (Fig. 4). At a radioligand concentration of $3.5 \mathrm{nM}$, and competitor concentration of $3.5 \mu \mathrm{M}$, significant competition $(P<0.001)$ was displayed by all analogues, precursor, and metabolite of angiotensin II studied. While their affinity for the AII binding site was generally comparable, that of $\mathrm{Sar}^{1}$-Thr ${ }^{8}$-AII was slightly higher than that of Sar ${ }^{1}$-Ala ${ }^{8}$-AII $(P<0.025)$, and angiotensin III was better than angiotensin $\mathrm{I}(P<0.01)$ in this respect. Unrelated peptides of similar molecular weight (bradykinin, ACTH [1-10] fragment) caused no significant competition with the radioligand for its binding sites.

\section{Discussion}

This study documents for the first time the profile of AII binding sites along the rat nephron. Specific binding was identified in most segments but was highest in the proximal tubule. Binding in PCT was dependent on tubule length and ligand concentration and was saturable, with an apparent maximal binding capacity of $\sim 300 \mathrm{amol} \cdot \mathrm{cm}^{-1}$. Specific binding was unstable at physiologic temperatu $\left(37^{\circ} \mathrm{C}\right)$, while nonspecific binding progressively increased with time. Furthermore, beyond $15 \mathrm{~min}$ of incubation,

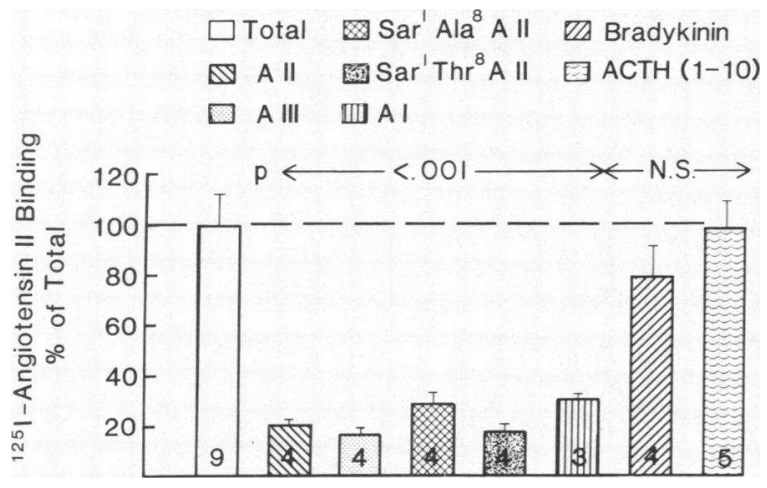

Figure 4. Competition of peptides with ${ }^{125}$ I-AII for binding sites in the PCT. Significant competition $(P<0.001)$ was displayed by angiotensin II precursor, metabolite, and synthetic analogues, but not by either bradykinin or ACTH [1-10] fragment. Number of animals is given in bars. nonspecific binding tended to be higher at $37^{\circ} \mathrm{C}$ compared with $25^{\circ} \mathrm{C}$. Similar temperature-related changes in binding characteristics were reported by Kitamura et al. (16), who studied angiotensin II binding to rat glomeruli.

Our results indicate that AII binding was highest in the proximal convoluted tubule. A high degree of binding to this segment is consistent with the findings of studies using cortical membrane preparations (10-13), and cultures of proximal tubule cells (14). Medullary receptors for angiotensin II have not been well characterized before. On the basis of autoradiographic studies, Gehlert et al. (17) and Mendelsohn et al. (18) have suggested the presence of binding sites in the medulla of rat and dog kidney. However, no specific tubular segment localization was attempted. The present study is the first to identify and quantitate AII binding in specific medullary tubule segments. Binding in the thick ascending limb of Henle's loop was higher in the cortical than in the medullary portion, and was intermediate between that measured in proximal and collecting tubules.

The profile of AII binding sites defined in this report is also consistent with the known sites of direct tubular actions of the hormone. Several studies have shown an effect of AII on fluid transport in the PCT $(2,7)$. The peptide also increases phospholipid turnover in microdissected PCTs as evidenced by enhanced ${ }^{32} \mathrm{P}$ labeling of phosphatidylcholine and phosphatidylinositol (19). Evidence for distal effects of AII is less direct (2), but identification of specific binding sites in distal segments in this paper suggests that the alterations reported in clearance studies may, at least in part, reflect direct tubular effects (2).

When intact tubule segments are used, binding is presumed to occur predominantly to basolateral membranes of tubular cells, which are directly exposed to the ligand. Studies using renal membrane preparations have, however, described both luminal and basolateral membrane binding of AII (10-13). To explore luminal binding sites in isolated tubules, the cells were permeabilized and disrupted by incubation in a hypotonic medium. This procedure led to a significant increase in specific AII binding, with a more modest increment in nonspecific binding. This increase in specific binding after cell disruption may reflect exposure of additional binding sites likely located at the luminal membrane, as the radioligand gains access to these sites as well. Luminal binding of angiotensin II may be a prelude to its degradation by brush border enzymes in the PCT, a major site of metabolism of the filtered peptide (20), whereas binding to basolateral membrane receptors probably precedes its biologic effect on the renal cell. Results of segmental distribution described above indicating preferential binding to the PCT and the diluting segment support this view: the best known effects of AII on the renal tubule take place in these same regions of the nephron (2).

In summary, in this study we have determined the profile of AII binding sites along the rat nephron. Binding was highest in the PCT, a segment known to be a target site for the effects of the hormone on transport and metabolism, but was also identified in segments previously unsuspected of being sites of action of this peptide. The role of angiotensin II in the function of the latter requires further study.

\section{Acknowledgments}

This work has been supported by grants from the Chicago Heart Association and the National Kidney Foundation of Illinois (Dr. Mujais), and by grants AM 13601 and AM 19250 from the National Institutes of Health (Dr. Katz). 


\section{References}

1. Brenner, B. M., N. Schor, and I. Ichikawa. 1982. Role of angiotensin II in the physiologic regulation of glomerular filtration. Am. J. Cardiol. 49:1430-1433.

2. Harris, P. J., and L. G. Navar. 1985. Tubular transport responses to angiotensin. Am. J. Physiol. 248:F621-F630.

3. Steven, K. 1974. Effect of peritubular infusion of angiotensin II on rat proximal nephron functions. Kidney Int. 6:73-80.

4. Vander, A. J. 1963. Inhibition of distal tubular reabsorption by angiotensin II. Am. J. Physiol. 205:133-138.

5. Harris, P. J., and J. A. Young. 1977. Dose-dependent stimulation and inhibition of proximal tubular sodium reabsorption by angiotensin II in the rat kidney. Pfluegers Arch. Eur. J. Physiol. 367: 295-297.

6. Burg, M., and J. Orloff. 1968. Control of fluid absorption in the renal proximal tubule. J. Clin. Invest. 47:2016-2024.

7. Schuster, V. L., J. P. Kokko, and H. R. Jacobson. 1984. Angiotensin II directly stimulates sodium transport in the rabbit proximal convoluted tubule. J. Clin. Invest. 73:507-515.

8. Ballermann, B. J., K. L. Skorecki, and B. M. Brenner. 1984. Reduced glomerular angiotensin II receptor density in early untreated diabetes mellitus in the rat. Am. J. Physiol. 247:F110-F116.

9. Brown, C. A., R. M. Zusman, and E. Haber. 1980. Identification of an angiotensin receptor in rabbit renomedullary interstitial cells in tissue culture. Circ. Res. 46:802-807.

10. Brown, G. P., and J. G. Douglas. 1983. Angiotensin II binding sites in rat and primate isolated renal tubular basolateral membranes. Endocrinology. 112:2007-2014.

11. Brown, G. P., and J. G. Douglas. 1982. Angiotensin II binding sites on isolated rat renal brush border membranes. Endocrinology. 111: 1830-1836.
12. Cox, H. M., K. A. Munday, and J. A. Poat. 1983. The binding of ${ }^{125}$ I-angiotensin Il to rat renal epithelial cell membrane. Br. J. Pharmacol. 79:63-70.

13. Cox, H. M., K. A. Munday, and J. A. Poat. 1984. Location of ${ }^{125} \mathrm{I}$ )-angiotensin II receptors on rat kidney cortex epithelial cells. $\mathrm{Br}$. $\mathrm{J}$. Pharmacol. 82:891-895.

14. Simpson, R. V., and T. L. Goodfriend. 1984. Angiotensin and prostaglandin interactions in cultured kidney tubules. J. Lab. Clin. Med. 103:255-271.

15. Mujais, S. K., M. A. Chekal, W. J. Jones, J. P. Hayslett, and A. I. Katz. 1985. Modulation of renal Na-K-ATPase by aldosterone: Effect of high physiologic levels on enzyme activity in isolated rat and rabbit tubules. J. Clin. Invest. 75:170-176.

16. Kitamura, E., R. Kikkawa, Y. Fujiwara, T. Imai, and Y. Shigeta. 1984. Temperature-dependent negative cooperativity among angiotensin II receptors of isolated rat glomeruli. Biochim. Biophys. Acta. 800:6674.

17. Gehlert, D. R., R. C. Speth, and J. K. Wamsley. 1984. In vitro autoradiographic localization of $\left({ }^{125} \mathrm{I}\right)$-angiotensin II binding sites in the rat and dog kidney. Peptides. 5:1043-1048.

18. Mendelsohn, F. A. O., G. Aguilera, J. M. Saavedra, R. Quirion, and K. J. Catt. 1983. Characteristics and regulation of angiotensin II receptors in pituitary, circumventricular organs and kidney. Clin. Exp. Hypertension. 5:1081-1097.

19. Wirthensohn, G., and W. G. Guder. 1985. Stimulation of phospholipid turnover by angiotensin II and phenylephrine in proximal convoluted tubules microdissected from mouse nephron. Pfluegers Arch. Eur. J. Physiol. 404:94-96.

20. Peterson, D. R., G. Chrabaszca, W. R. Peterson, and S. Oparil. 1979. Mechanism for renal tubular handling of angiotensin. Am. J. Physiol. 236:F365-F372. 